groups, but rumours persist that many senior employees will opt to retire rather than relocate.

That would be a significant blow to an agency that is already stretched. The NSF's budget has grown slowly but steadily in recent years, reaching $\$ 7.3$ billion in fiscal year 2015 . But even though the number of grant proposals submitted to the agency has risen by $65 \%$ over the past 15 years, the NSF has seen only a $20 \%$ increase in the number of full-time employees.
The resulting increase in workload has affected staff morale. A 2014 survey by the US Office of Personnel Management found that only $45 \%$ of NSF employees felt that the agency's leadership generated "high levels of motivation and commitment in the workforce", compared with $53 \%$ in 2010 . And just over one-third of workers were negative about the opportunities available for getting a better job at the agency.
As Córdova enters the second year of her six-year term, the challenges ahead are clear.

Eugene Skolnikoff, a political scientist at the Massachusetts Institute of Technology in Cambridge, says that winning and maintaining the trust of the scientific community gives an NSF director clear authority to negotiate with Congress. "The best NSF directors," he says, "have been the ones who really got the staff and the scientists behind their vision."

\title{
DNA clock proves tough to set
}

\section{Geneticists meet to work out why the rate of mutation in the human genome is hard to pin down.}

\section{BY EWEN CALLAWAY}

$\mathrm{M}$ athematicians keep refining $\pi$ even though they know it to more than 12 trillion digits; physicists beat themselves up because they cannot pin down the gravitational constant beyond three significant figures. Geneticists, by contrast, are having trouble deciding between one measure of how fast human DNA mutates and another that is half that rate.

The rate is key to calibrating the 'molecular clock' that puts DNA-based dates on events in evolutionary history. So at an intimate meeting in Leipzig, Germany, on 25-27 February, a dozen speakers puzzled over why calculations of the rate at which sequence changes pop up in human DNA have been so much lower in recent years than previously. They also pondered why the rate seems to fluctuate over time. The meeting drew not only evolutionary geneticists, but also researchers with an interest in cancer and reproductive biology - fields in which mutations have a central role.

"Mutation is ultimately the source of all heritable diseases and all biological adaptations, so understanding the rate at which mutations evolve is a fundamental question," says Molly Przeworski, a population geneticist at Columbia University in New York City who attended the Human Mutation Rate Meeting.

Researchers tried to put a number on the human mutation rate even before they

knew that genetic information is encoded in DNA. In the 1930s, pioneering geneticist J. B. S. Haldane came up with a good estimate by measuring how the mutations responsible for haemophilia appeared in extended families. Later estimates of the mutation rate counted the differences between stretches of DNA and protein amino-acid sequences in humans and those in chimpanzees or other apes, and then divided the number of differences by the time that has elapsed since the species' most recent common ancestor appeared in the fossil record. These estimates were clouded by the patchiness of the fossil record, but researchers eventually settled on a consensus: each DNA

"The fact that
the clock is so
uncertain is very
problematic
for us."

letter, on average, mutates once every billion years. That is a "suspiciously round number", molecular anthropologist Linda Vigilant of the Max Planck Institute for Evolutionary Anthropology in Leipzig told Nature in 2012 (see Nature 489, 343-344; 2012).

In the past six years, more-direct measurements using 'next-generation' DNA sequencing have come up with quite different estimates. A number of studies have compared entire genomes of parents and their children and calculated a mutation rate that consistently comes to about half that of the last-commonancestor method.
A slower molecular clock worked well to harmonize genetic and archaeological estimates for dates of key events in human evolution, such as migrations out of Africa and around the rest of the world ${ }^{1}$. But calculations using the slow clock gave nonsensical results when extended further back in time - positing, for example, that the most recent common ancestor of apes and monkeys could have encountered dinosaurs. Reluctant to abandon the older numbers completely, many researchers have started hedging their bets in papers, presenting multiple dates for evolutionary events depending on whether mutation is assumed to be fast, slow or somewhere in between.

Last year, population geneticist David Reich of Harvard Medical School in Boston, Massachusetts, and his colleagues compared the genome of a 45,000-year-old human from Siberia with genomes of modern humans and came up with the lower mutation rate $^{2}$. Yet just before the Leipzig meeting, which Reich coorganized with Kay Prüfer of the Max Planck Institute for Evolutionary Anthropology, his team published a preprint article $\mathrm{e}^{3}$ that calculated an intermediate mutation rate by looking at differences between paired stretches of chromosomes in modern individuals (which, like two separate individuals' DNA, must ultimately trace back to a common ancestor). Reich is at a loss to explain the discrepancy. "The fact that the clock is so uncertain is very problematic for us," he says. "It means that the

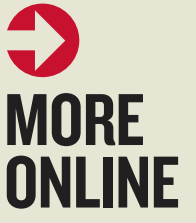

PICTURES OF THE MONTH

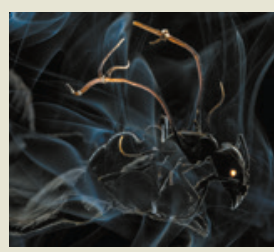

Zombie ants, mummified seals and a gorilla punch go.nature.com/ $\mathrm{mn} 4 \mathrm{fsx}$

\section{MORE NEWS}

- No link between psychedelics and psychosis go.nature.com/cwramz - How Ebola survivors mustered an immune defence go.nature.com/6d3upn - Complex societies evolved without belief in all-powerful deity go.nature.com/kumjxo
STORY OF THE WEEK

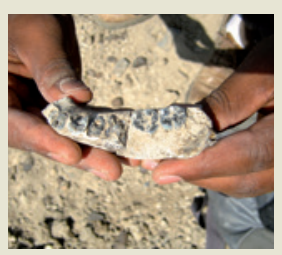

Ethiopian jawbone may mark dawn of humankind go.nature.com/ icyibm 
$\checkmark$ dates we get out of genetics are really quite embarrassingly bad and uncertain."

Reich hoped that even if the meeting did not reach a consensus on mutation rate, it would highlight the research that is needed to move forward. He and Prüfer kicked off the meeting by polling attendees on their favoured rate, and found that the lower figure had gained popularity, but there was still a wide spread of opinions.

Increasingly, Reich and others conclude that the human mutation rate has fluctuated over millions of years. Much of the discussion at the meeting revolved around when it accelerated and decelerated - and why. Evolutionary changes in metabolism or reproductive biology are both possible causes. Aylwyn Scally, a population geneticist at the University of Cambridge, UK, thinks that the common ancestor of great apes, which lived between 20 million and 12 million years ago, had longer generations than its relatives on the monkey branch of the primate family tree. That would have slowed mutation: a longer generation would lead to fewer mutations per year, on average.

Medical-minded geneticists also fret about mutation rates. Meeting attendee Michael Stratton, director of the Wellcome Trust Sanger Institute in Hinxton, UK, is a cancer geneticist who studies the causes of DNA mutations. Environmental agents such as tobacco smoke trigger some cancers, but others are caused by the normal biochemical operations of cells - through processes that are little-known, says Stratton. Working out what these are could explain fluctuations in the mutation rate.

Reproductive biologists are also interested in the human mutation rate - in part because they have found that some diseases are more common in the children of older men than of younger ones. Sperm are produced throughout a man's life, whereas women are born with a full array of eggs. The constant division of sperm precursor cells means that men tend to pass on more new mutations to their offspring than women - four times as many, according to a 2012 estimate $e^{4}$ - and older fathers transmit more mutations than young ones. This means that changes in the biology of sperm production or paternal age over evolutionary time could influence mutation rate.

Even though the human mutation rate is still uncertain and unstable, Reich proposed at the meeting that researchers use the slower value for their work, at least until better data come along. Just don't think of it as a constant, he cautions: "This is not the speed of light. This is not physics." -

\footnotetext{
1. Scally, A. \& Durbin, R. Nature Rev. Genet. 13 745-753 (2012)

2. Fu, Q. et al. Nature 514, 445-449 (2014).

3. Lipson. M. et al. Preprint at http://dx.doi. org/10.1101/015560 (2015)

4. Kong, A. et al. Nature 488, 471-475 (2012).
}

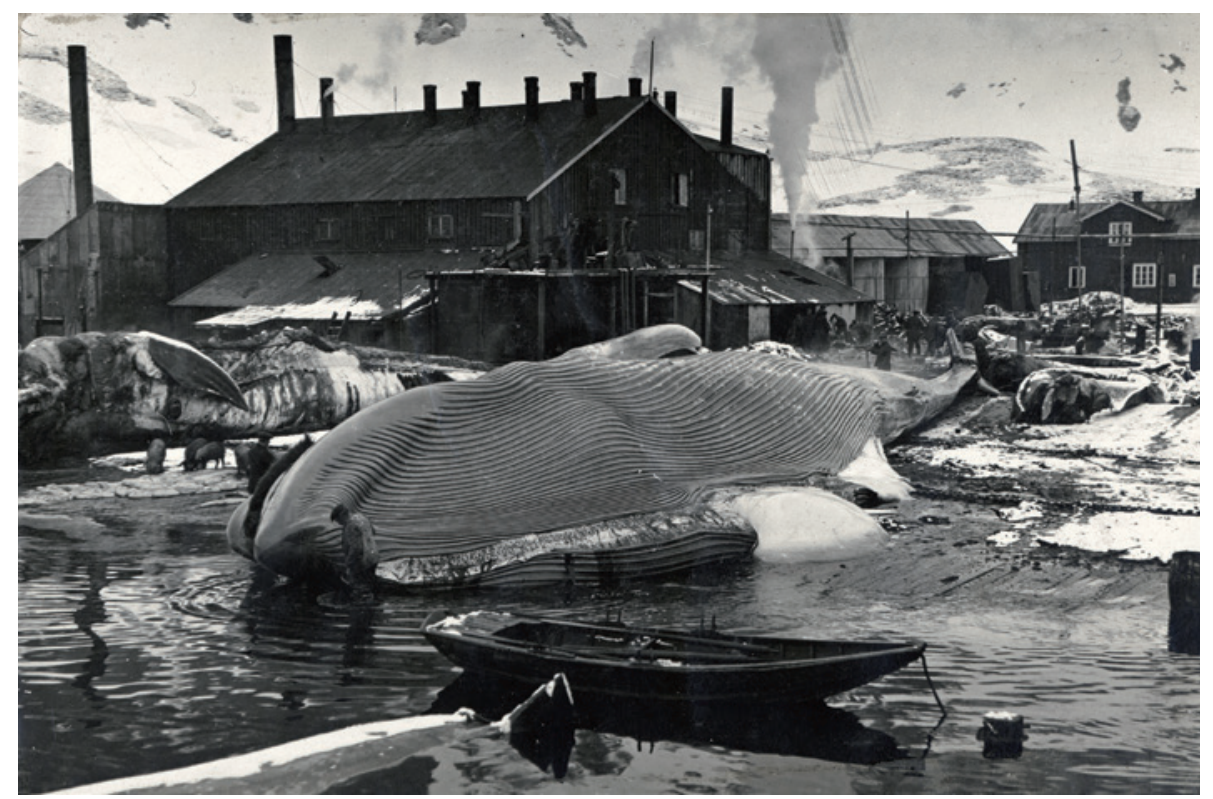

The Grytviken whaling station on South Georgia island in the First World War. It has long been abandoned.

\section{MARINE ECOLOGY}

\section{World's whaling slaughter tallied}

\section{Commercial hunting wiped out almost three million animals last century.}

\section{BY DANIEL CRESSEY}

$\mathrm{T}$ The first global estimate of the number of whales killed by industrial harvesting last century reveals that nearly 3 million cetaceans were wiped out in what may have been the largest cull of any animal — in terms of total biomass - in human history.

The devastation wrought on whales by twentieth-century hunting is well documented. By some estimates, sperm whales have been driven down to one-third of their pre-whaling population, and blue whales have been depleted by up to $90 \%$. Although some populations, such as minke whales, have largely recovered, others - including the North Atlantic right whale and the Antarctic blue whale - now hover on the brink of extinction.

But researchers had hesitated to put a number on the global scale of the slaughter. That was largely because they did not trust some of the information in the databases of the International Whaling Commission, the body that compiles countries' catches and that manages whaling and whale conservation, says Robert Rocha, director of science at the New Bedford Whaling Museum in Massachusetts.
Rocha, together with fellow researchers Phillip Clapham and Yulia Ivashchenko of the National Marine Fisheries Service in Seattle, Washington, has now done the maths, in a paper published last week in Marine Fisheries Review (R. C. Rocha Jr, P. J. Clapham and Y. V. Ivashchenko Mar. Fish. Rev. 76, 37-48; 2014). "When we started adding it all up, it was astonishing," Rocha says.

The researchers estimate that, between 1900 and 1999, 2.9 million whales were killed by the whaling industry: 276,442 in the North Atlantic, 563,696 in the North Pacific and 2,053,956 in the Southern Hemisphere. Other famous examples of animal hunting may have killed greater numbers of creatures - such as hunting in North America that devastated bison and wiped out passenger pigeons. But in terms of sheer biomass, twentieth-century whaling beat them all, Rocha estimates.

"The total number of whales we killed is a really important number. It does make a difference to what we do now: it tells us the number of whales the oceans might be able to support," says Stephen Palumbi, a marine ecologist at Stanford University in California. He thinks that 2.9 million whale deaths is a "believable" figure. 